\title{
Authentic Education: Visualising Education in a Deeper Perspective
}

\author{
Chandana Watagodakumbura ${ }^{1, *}$ \\ ${ }^{1}$ School of Electrical and Computer Engineering, RMIT University, Melbourne, Australia \\ *Correspondence: Chandana Watagodakumbura, School of Electrical and Computer Engineering, RMIT University \\ (GPO BOX 2476), Melbourne, Vic, 3001, Australia. Tel: 61-3-9925-2092. E-mail: \\ chandana.watagodakumbura@rmit.edu.au
}

Received: April 26, 2013

Accepted: May 20, 2013

Online Published: May 28, 2013

doi:10.5430/wje.v3n3p1

URL: http://dx.doi.org/10.5430/wje.v3n3p1

\begin{abstract}
Authentic education is presented in this paper from a multidisciplinary perspective; it is viewed and discussed mainly from the perspectives of psychology, pedagogy, neuroscience and machine learning. It addresses the individual psychological and neurological differences and guide individuals to reach higher levels of human developments. Especially, high emotional, intellectual and imaginational sensitivities are accepted as enriching a neurodiverse society, rather than constraining it. Further, the learners undergo a deep-learning and critical thinking process in a manner that is natural to human brain functioning as a parallel processor, as opposed to a robotic machine that operates sequentially at a high speed. As studies in neuroscience reveal, when learning takes place deeply, dendrites within the human brain are capable of growing into denser networks giving a physical meaning to our learning. Authentic education unifies different perspectives from multiple disciplinary areas in to a useful measure that can be implemented in educational practice. In this way, we visualise education in a deeper sense that is not seen usually in a contemporary society, and pave the way for a significant positive social change.
\end{abstract}

Keywords: authentic education; gifted education; human development; deep learning; neurodiversity; significant social change

\section{Introduction}

\subsection{Definitions of the General Term Education}

We come across the diverse forms definitions of the general term education in numerous related literatures. In many cases, it carries a subjective meaning; the writers usually view it biased to their strongest thoughts, while the readers make a meaning based on their personal experiences and social and educational backgrounds. However, the notion carries immense significance and requires more elaborations, as the author attempts in this paper to achieve it utilising a deeper and multidisciplinary approach to understanding and defining it.

\subsection{Ambiguities in Understanding and Defining Education}

When we traverse through high volumes of literature available generally on education or any related disciplines, there are more times we get conflicted or unclarified than not. We seem to get very useful isolated information but not very well integrated or generalised material in a meaningful manner in which we can digest and absorb further, insightfully. Or at least we feel that we can critically analyse them to form or synthesis more useful inferences. Each education institute define the standards it conforms in providing the educational services. These institutes then attempt to impart the understood standards to their academic staff so that they can practice them in the classroom. Each department or school within an institute will have their own reservations in conforming to standards it maintains and practices. Each academic member combines what they perceived as education, or what they have experienced in the past as education, and the standards imparted on them by the institutes to unfold the teaching-learning process. Different academic members do assess students based on their own understanding, or interpretation, of what education is all about and the students get their grades accordingly. Each individual student is different from the other fellow students and each will have their preferences, or likes and dislikes. Some students would enjoy the teaching-learning processes practiced by a certain academic on a certain subject area, but some other 
students do not like the teaching-learning style of this particular academic. The latter group would achieve a better grade for the course, or unit, on a new attempt, possibly within a new teaching-learning environment. Many students may feel the environment in a more neutral manner, possibly due to having no benchmark to be based on, or compare with. What the author is trying to get here is to question the authenticity of education the students receive in the face of differences within the students, academics and their perceptions on education and teaching-learning practices, course materials, and standards enforced by each departmental unit and the institute.

\section{Authentic Education: Essentially a Multidisciplinary Viewpoint}

The notion "authentic education" should be viewed from a multi-disciplinary perspective. Educationists discuss about deep versus surface learning, critical thinking, Blooms taxonomy, learning-styles and so on and so forth. Psychologists discuss about learning disabilities, special and gifted education, existential depression in gifted adults, emotional and other sensitivities, sequential and visual spatial learners, personality, or human development and so on and so forth. Neuroscientists study and discuss about brain structures and how they relate to learning. Computer scientists study about artificial neural networks and try to emulate human brain functions using computers. Investors and businesses compete for human skills as if they receive them from robots, finely programmed in a repetitive, sequential, or non-creative manner, though operating at higher speeds, to maximise their profits. These different perspectives of different stakeholders put the onlookers and students in a very vague situation, if not a highly confused one. The challenge is to integrate and prioritise all these perspectives to understand and define authentic education in a sensible and meaningful manner. The task truly has a multidimensional perspective as is the case in most real world problems in a very dynamic and ever changing environment. If we disregard a single dimension from the equation, we are likely get a less optimal or distorted perspective of the issue. In the real world, some of these dimensions are neglected while allowing some others to dominate, not necessarily in the order of how significant each of these perspectives is to the outcome, or sustainable social development. To understand what authentic education is, we need to look at it from each of the aforementioned different perspectives in the least.

Let us take each of the aforementioned viewpoints from which authentic education can be seen and addressed in depth in the following sections to figure out the real nature of the related issues.

\subsection{Authentic Education from Important Psychological, Neurological and Human Development Viewpoints}

\subsubsection{Psychological and Neurological Characterisation of Individuals and Learning}

Psychologists categorise different learning styles of individuals into two broad types: auditory sequential learning and visual spatial learning (Silverman, 2002). The students with preference to the former learning style are more inclined to have extrovert personalities while the students with preference to the latter learning style are inclined to possess introvert personalities. Furthermore, visual special learners are generally categorised as gifted and creative individuals who usually show a very high level of emotional sensitivity. Well known Polish psychologist Kazimierz Dabrowski (Dabrowski, 1977) referred to gifted personnel, or those with high developmental potential as human beings, as having most prominently emotional, intellectual and imaginational over-excitabilities, meaning high intensities, and providing somewhat unusual responses to stimuli; the term high developmental potential indicates that these individual have the potential to become highly ethical, empathetic and creative human beings, overcoming their high over-excitabilities. In a similar vein, the famous psychologist Abraham Maslow referred to personnel with high development potential as self-actualising individuals; at the highest level, these individuals become highly creative and self-actualised human beings who become aware of reality as it is, facing it boldly with much less inhibitions (Maslow, 1968). Maslow also pointed out that most of the human beings do not reach higher levels of development that are inherent to human nature due to lack of conducive social and educational environments (Maslow, 1993). Psychologists working with gifted children and adults promote special education programs for gifted individuals as the traditional education environments create a negative impact on those individuals and their development. That is, we can infer that individuals with preference to auditory sequential learning style are more likely to survive positively in a traditional educational environment. With the term traditional educational environment, I mean what we have been doing for over hundreds of years in education. A person knowledgeable in a particular area speaks regularly for a period of time in front of usually a large gathering of students who are later assessed for their competence, typically with a written examination at the end of the study period. The assessments are usually based on the recall of facts as opposed to an individual's ability to analyse and synthesise, the so called higher-order learning parameters. The key feature of this approach is that all the students are expected to engage in an identical manner to the unit, or course, disregarding any diversity within the student cohort as learners. Especially when the class size is large, it becomes very difficult to pay attention on each individual student. From a 
teaching-learning perspective, we tend to quite dramatically simplify the environment with the assumption that all the students learn in the same way and they all respond to the assessments in the same manner. We usually do not appreciate that students may have different learning styles based on their psychological as well as neurological characteristics and that there would be differences in meeting the assessment requirements. We have enough evidence that some student categories, such as those with preference to visual special learning styles, do not do their best in timed tests and multiple choice question tests. These students are usually better abstract thinkers and the said type of assessment would not test their abilities appropriately. Thus the grades awarded to the students are biased heavily on the methodology followed by the specific teacher who conducted the course, and to some extent on the standards and regulations imparted by the governing academic administrative unit, or organisation. The students may have been tested for the ability to merely recall the facts; they may have been tested for application of knowledge; they may have been tested for ability to analyse; they may have been tested for ability to synthesise. But the grades do not differentiate them, whether the testing was more inclined for higher-order learning or lower-order learning. Research psychologists have provided enough evidence to accept that those who are capable of and motivated in recalling facts are not necessarily good in analysing or synthesising information. What we end up under these circumstances is that the authenticity of student learning is greatly challenged and misinterpreted.

The author would like to view the categorisation of auditory sequential and visual spatial learners from a different perspective. We see in our vicinity the different types of tasks we perform daily. They can be broadly categorised into tasks of implementation and tasks of integration. The tasks of implementation have to be attended by performing a step at a time, more or less in a routine manner, whereas tasks of integration have to be performed with more contemplative and creative manner, possibly taking more time to see the big picture and also to see things from different perspectives. Personnel who find themselves at ease relatively in attending tasks of implementation can be categorised as implementers while those who find intrinsically at ease relatively in attending tasks of integrations can be called integrators. If we go through the personality traits of auditory sequential and visual spatial learners carefully, it would not be hard to realise that implementers are more likely to fall into the category of auditory sequential learners while integrators are likely to fall into the category of visual special learners. The important fact is that in our environments we have both categories of tasks present and the society needs personnel of more inclined personality traits of integrators as well as implementers. The challenge in the provision of authentic education is to identify these personality traits of individuals accurately and guide them to suitable career paths so they find themselves more at ease intrinsically, or naturally, resulting more integrated and happier human minds, and the society benefiting from more efficient and effective human resources utilisation. If we look around our environment, we see that majority of tasks we engage in daily are of implementation type and comparatively smaller percentage is of the type integration. This fact aligns well with the research findings that, in general, two thirds of the personnel are of auditory sequential type learners while the other one third is of the visual spatial type learners. It is important to understand that there is no hardline demarcation between auditory sequential and visual spatial learning styles, or between implementer and integrator work categories, or between extroverted and introverted personality types. It is that, an individual would possess more personality traits of one type than the other. In other words, it is not a strict two state or ON/OFF type categorisation; rather it can be seen as a continuous scale where an individual may lie anywhere on it. We can also infer that there is more likelihood that an integrator type personality gets trapped in an implementation type task, or career, resulting a struggle or unhappy work environment for the individual. This is despite the fact that visual spatial learners or integrator type personalities possessing advanced abstract thinking and spatial capabilities.

\subsubsection{Negative Images Pertaining to Gifted Individuals}

We do also have significant research findings that visual spatial learners, or gifted learners, as they are commonly categorised, more likely to develop negative images of themselves as well as of the society at large when their requirements and preferences are not met for a prolonged period of time. These situations even extend to cause them psychological problems, sometimes leading to existential depression in some individuals during certain stages of their lives. (Webb, 2008) According to the research findings, it is also possible that, due to their heightened sensitivity, they demonstrate frustrated behaviours at times. Kazimierz Dabrowski (Dabrowski, 1972) even refers to individuals of these traits as "psychoneurotics" and identified the underlying process of psychoneuroses as a path to higher level of human development. Dabrowski (Dabrowski, 1970) has highlighted this phenomenon of psychoneuroses as the Theory of Positive Disintegration (TPD) in which he identified individuals with high developmental potential need to disintegrate from lower levels of development before re-integrating at higher levels of development. Some scholars have also raised the issue of misdiagnosing gifted individuals as having disorders or learning disabilities in significant numbers (Webb, 2005; Silverman, 2004); these incidents could occur, most 
probably, due to misjudgement of gifted individuals' highly intense and unusual reactions to some social situations. The issue the author is trying to highlight here is that whether we can, as educators and parents, identify and address the issues and requirements of these sensitive and gifted personnel. These personalities are more likely to demonstrate psychological imbalances, or deviate from standard behaviour, compared to the personnel of other personalities. Ideally, the education system needs to address the needs of different personality types in identifying their strengths and fostering them as means of developing authentic personalities. When these authentic personalities are actualised, any mismatch between who they are really and what is common or seen in the environment is minimised. They also learn to be more resilient of any discrepancy that may occur.

\subsubsection{Accepting Neurodiversity}

We have seen the significance and one very important feature of authentic education. It essentially means that we are giving due recognition for different personality types, based on the broad concept of neurodiversity, and thereby for diverse strengths and learning styles, so that each student maximises the effectiveness of his/her learning experience in accordance to his/her personality traits. This is a totally different approach to what we commonly practice now, literally trying to fit one size to all, creating a significant mismatch and discrepancy. Psychologists emphasise on embracing the diversity within the human species as opposed to fitting them all into one hypothetical creature possessing imaginary qualities and features (Armstrong, 2011). The idea of neurodiversity is as if the human species is like a rainforest, consisting of diverse plants and trees, giving it its much needed equilibrium with nature and at the same time causing it very attractive to botanists and other interested parties.

\subsubsection{Special Learning Environments for the Gifted as the Solution}

There is another significant observation in relation to implementing an authentic education system that we have those professionals working as psychologists and proposing special education programmes for gifted personnel and a separate group of educationists who strive to make students learn deeply with enhanced understanding in general. What is essential is that we need to get the attention of the general educators on why a special group of psychologists promoting special education programmes for gifted personnel. Is there a significant view-point that the general educators are missing out, completely or partially? General educators may need to consider, or at least are directed to give due considerations for different learning styles preferred by different student categories. We have educators in different disciplines, such as disciplines related to natural sciences, social sciences, liberal arts or technology, etc., but usually see that the pedagogical principles are only explicitly practiced by those who are involved directly in the discipline of pedagogy. It is not uncommon that some educators, who are not practicing in the discipline of pedagogy, express themselves cynically towards pedagogical principles, let alone considering psychological traits of individual students. However, we may ask ourselves - "Is it merely a learning style that is important". We need to go beyond these learning styles in understanding more in depth the personality traits as done by psychologists. This essentially leads to a multi-disciplinary perspective in providing education, or more correctly providing authentic education, or developing authentic personalities - an authentic whole human being. That is, trying to understand and categorise students in accordance to their personality traits, as done by psychologists, and matching the learning experiences, and thereby career options, to suit them are significant aspects of an authentic educational framework.

\subsection{Authentic Education from Important Pedagogical Viewpoints}

\subsubsection{Deep versus Surface Learning}

Education researchers have identified and revealed that learning can take place in the form of deep-learning, surface learning or strategic learning (Biggs, 2003; Entwistle, 1998). In general, we expect all students to follow a deep-learning path in which students maximise the effectiveness of learning outcomes. From a traditional perspective, education suggested passing facts from a knowledgeable person to a mass gathering. This was specifically true when information technologies and other related technologies of printing and publishing were not as developed as now and even facts were difficult to disseminate. So the general competition was to access facts or information rather than understanding or digesting them thoroughly. Assessment, in return, was also based on testing the ability to recall facts through pure memorisation. These situations, in general, encouraged the learners to follow a surface learning approach in the teaching-learning process. This trend continued for years, possibly hundreds in number, and we still have some significant trails in a very large number of environments. We as educators, tend to follow the practices we have widely seen as students, despite large scale training provided on the contemporary pedagogical principles and practices. We as academic experts of a disciplinary area tend to believe that if we learned and became experts following certain teaching-learning practices, what is wrong, or defective, with those practices; the same practices can be blindly inflicted on the next generation learners. If you have become an expert and are highly successful in your career, you hardly reflect and see how fortunate your are that prevailing conditions and circumstances suited 
you to be triumphant; there could be many who were not so fortunate, despite being highly capable in many other ways that were counted. Haven't we been the opportunists, in a society of survival of the fittest, the law of the jungle? Sometime we are hugely pre-meditated that we even do not realise the point that we could improve our practices considerably to address some pressing issues. In pursuit of authentic education, we need to get some deeply held but quite challenged notions addressed straight in the light of enlightening findings in pedagogy and related disciplines such as psychology. Surface learning only helps learners to possibly achieve and develop some very basic level of knowledge and skill, which are not penetrating enough to build strong authentic personalities as required by the modern society to address some of its pressing needs. Such practices have highly detrimental impact on those who have natural inclination to engage deeply, as demonstrated by gifted and creative personnel with high developmental potential. Historical work pioneered by Leta Hollingworth provides evidence that the issues we raise existed for decades, if not for centuries. Educators face a great challenge in guiding learners in a deep learning path as promoted by education researchers as a prime necessity. The challenge is not only of finding new methodologies to implement a deep learning framework, but also of shedding some long standing practices widely employed in a different era when the circumstances were considerably different. Failure to implement a proper and well thought out deep learning framework may prompt learners to follow a strategic learning path in which they are purely guided by assessment and obtaining merely high grades. If the assessments fail to capture a deep learning focus, it is difficult to guide learners to deep-learning, as they naturally get guided by assessment criteria (Biggs 2003; Ramsden, 2003). It is not uncommon to come across some courses in which learning and assessment do not converge, confusing the learners, especially those who fall into gifted category and look for more purposeful directions, on what to emulate.

\subsubsection{Teacher Centred versus Student Centred Learning}

Education researchers also encourage a paradigm shift from a teacher-centred to student-centred or learner-centred practices of teaching-learning (DeLyser, 2003). In a teacher-centred approach, a knowledgeable person possibly addresses a large gathering of students almost in a one-way communication manner. The teacher is at the centre of attention in the teaching-learning process and educational environment. The students become passive listeners. In pedagogy, the term didactic teaching is used to reflect this situation. The students would possible try to memorise and jot-down what the teacher said hurriedly so that this information can later be used for answering assessment question. Getting and providing feedback on student learning, as to what degree or depth the students learned, in a two-way communication manner does not take place in this situation. In contrast, in student-centred learning, the centre of attention is the student in a teaching-learning environment. What is important is how well the students learned in the process and this feedback is of immense value. The communication essentially takes place in a two-way manner. Ideally, the class size is relatively smaller so that bi-directional communication is possible. Students question the material presented whenever necessary and engage more actively in the teaching-learning process. In pedagogy, this scenario is referred to as a dialectic teaching-learning process. As we can see, the dialectic approach has a deeper and critical focus to learning, while the didactic approach is more likely to produce a surface approach to learning. We can also see student-centred learning from another important point of view as well. That is, it is possible that individual students get more attention from the teacher to possibly get individual feedback and individual issues addressed. Also, the teacher gets to know students individually based on the discussions they engage in, thus getting to know their personality traits. This learner-centred approach accommodates for a more authentic learning experience for each student, and at the same time, it caters for a more authentic evaluation of individual students.

\subsubsection{Constructivist Theory of Learning}

In pedagogy, one of the learning theories discussed popularly and widely is constructivist theory of learning. According to constructivist theory, learners individually make meaning from what they learn. They align new learning with their existing knowledge and create new knowledge altogether. It contrasts from merely memorising facts, or surface learning; it is a process of constructing knowledge by active engagement. Every learner brings unique experience to the teaching-learning arena, and based on that, creates unique, authentic meaning from new learning. Thus, this theory of constructivism has authentic roots to education embedded in it. Since the leaner is engaged in creating new knowledge, he/she is not only deeply involved in the teaching-learning process, but also targets higher-order learning in the form of information synthesis, as highlighted in Bloom's taxonomy. If, we as educators can put constructivist theory into practice in the teaching-learning process, the individual learners are likely to receive a highly authentic, unique, educational experience.

\subsubsection{Critical Thinking in Education}

Deep learning can also be viewed from the eyes of those who promote introducing critical thinking in education. The 
need to introducing critical thinking explicitly in education suggests that traditional approaches to education generally follow a surface approach. Critical thinking in education promotes a deeper learning context in which clarity, precision, depth, breadth, assumptions make and different viewpoints of the material studied are highlighted (Paul and Elder, 2000). Sometimes, educators do not give due consideration to important parameters such as clarity, precision etc., especially when it comes to assessment. We need to be clear in what we are assessing, or what specific quality we are focusing on in assessing and also the possible answers from a number of different viewpoints. The statement is especially true when we are not assessing for recall of straightforward facts. We, as educators, sometimes are more focused in formulating a routine question than really understanding what we are assessing. We can simplify assessment by merely testing for recall of facts, but it does little help in providing authentic education to our learners. We need learners to go beyond memorising the specific vocabulary of the learning area, once a course of education is undertaken. We can also weigh the answers carefully for important measures such as clarity, precision, depth, breadth etc., thus giving more validation for our assessment. In the education arena, a common widely discussed debate is whether to introduce critical thinking as an explicit subject in education and what stage of education it should be introduced. When modern pedagogy emphasises deep-learning as the only effective approach to learning, it is not hard to understand that critical thinking should implicitly be part of the teaching-learning framework. However, introducing explicit courses on critical thinking in educational programs will do no harm; in fact it will highlight the need for critical thinking, or deep learning approaches for education. Also, introducing a course on learning or education in any program of study will be immensely useful for the learners as it will highlight much more clearly what is expected in the program of study and how to engage well in the process. Sometimes what happen is that those learners who follow surface or strategic approaches to learning may not even know the limitations of those approaches and that a richer educational experience with better overall yields is possible by pursuing a deep learning, or critical thinking, pathway.

\subsubsection{Bloom's Taxonomy and Higher-Order Learning}

Bloom's taxonomy is another commonly used measure to evaluate whether deep learning is focused in an education environment. According to Bloom's taxonomy, higher-order learning takes place when learners engage in analysis, synthesis and evaluation of material. When they engage only in memorisation and comprehension, it is said that lower-order learning takes place. In the middle of these two extremes, we have application of knowledge. In analysis, we break down into smaller components to study in detail, as that happens in divide and conquer. In synthesis, an opposite task of analysis is performed, generalising or forming a new idea, putting together a number of existing ones. In evaluation, we tend to see something from a number of different points of view, or a multidimensional perspective, to make an overall judgment. Especially in synthesis and evaluation, we observe learners use their creativity, as the term is usually used. The term creativity is usually used to specify that something new or innovative is formed; it could be a piece of art, a piece of writing, a lyric, or in general an idea, thought, generalisation or perspective being put forth in a physical format. The important point to note here is that in Bloom's taxonomy, creativity is a given the prominence as it should correctly be. Creativity is something we see elaborately in human species; it becomes a good yardstick to measure human ability, or learning. It is important on what end of the spectrum the educators are pushing the learners through. This is of immense significance when applied to assessment. When assessment focuses on testing higher-order learning as that happens in analysis, synthesis and evaluation, learners are directed towards engaging deeply and critically in the learning process. Directing assessment, or teaching-learning framework, purely towards the lower end of Bloom's spectrum - memorisation and comprehension - would not guide learners to achieve their best in their learning. Not just deprive learners of achieving their best, but also make some highly creative and capable learners less motivated, or demoralised in engagement in the learning process.

When we focus on reaching the higher end of Bloom's taxonomy by engaging in activities such as analysing, synthesising and evaluation, we usually leave behind a lasting experience behind us. These experiences can be recalled as many times one needs and when required without straining our heads much. On the other hand, if we focus on the lower end of Bloom's taxonomy, such as activities of memorisation and comprehension, we find it difficult to recall them possibly after a few days. A good real-life example is that, we as students, sometimes memorise and cram facts into our heads just prior to an examination, and find that these facts are no longer in our heads soon after the examination. It becomes a surface or strategic learning experience and the learners' success depending on the focus of the assessment and teaching-learning framework being used. If the learners can be adequately successful by following such practices, then they get motivated in continuing those practices, yielding a futile learning outcome on the whole. This signifies the need for more real and authentic educational experiences we need to send our learners through as that takes place when higher-order learning is targeted. 


\subsubsection{Generic Learning Attributes as Part of Assessment Metrics}

When we, as educators, focus on providing authentic education, how we assess our learners is a very important aspect that needs serious consideration. A large portion of learners get guided purely by the assessment criteria, and possibly only a small fraction pursues studies for the purpose of intrinsic motivation. As a result, it is of paramount importance that we understand and define learning objectives well, purposefully and clearly and align assessment criteria accordingly. In this regard, contrary to widely used contemporary practices, the author suggests that it is more appropriate that we assess learners' general learning attributes such as problem solving abilities, analytical or logical thinking skills, reflective or critical thinking abilities, abilities to generalise or synthesis, abilities to express or communicate clearly of one's standpoint, abilities to evaluate looking from different perspectives and so on and so forth. We deviate here from testing and allocating grades for a particular course, or unit, or subject area specific knowledge or facts; instead we suggest evaluating a generalised set of skills or attributes, representing higher-order learning, and that are meaningful irrespective of the area of study. More importantly, these generalised set of skills can be coherently linked to an individual's personality traits, suggesting that these evaluations yield more authentic value and meaning. In an undergraduate degree program of three years duration, we usually teach over twenty individual courses; a course or study area specific information tends not to retain in memory if not constantly refreshed or practiced. However, if an authentic approach to learning is pursued, it is more likely that, a generalised set of learning attributes or skills, as referred to earlier, would be developed and enhanced, possibly with more lasting memories. If we, as educators, give emphasis to these generic learning attributes throughout a study program, over a number of years, it is likely that learners would undergo a more authentic experience, continuously improving some useful generic skills, thus improving retention capacities of some specific learning material as well. If a certain learner desires to gain more specific knowledge and skills in a selected study area, he or she can quite easily and quickly achieve it, if the related generic learning attributes or skills are already well grasped.

The author would like to put forth a couple of significant features of assessing generalised learning skills in a study program. A learner's generalised learning attributes or skills evaluations can be based and compared with the same attribute evaluation of the same learner on a previous occasion, as opposed to comparing them with same attributes of the fellow students. There will be no competition between students to outperform others, but the challenge will be to improve one's own attribute or skill level from the previous level or status. This will be a very healthy environment fostering authentic and unique learning experience to meet learners' individual needs. Every learner will be engaged in a journey of intrinsic personal development as opposed to get guided by extrinsic benchmarks. The second significant feature of assessing generic learning attributes is that learners' higher-order learning attributes can be qualitatively evaluated with more validity than a precise quantitative percentage value, related to a specific disciplinary area and specific educational environment that are subject to debate. The accuracy that we can achieve in precise percentage values we award as the current common practice is quite debatable, if you consider them in depth. It is a qualitative level or standard achieved that matters; a higher percentage value obtained by aggregation of marks obtained from tests focusing lower-order learning is questionable for its validity; as the saying goes, it is not a matter of quantity, but a matter of quality. Additionally, we would not have learners who are good in course X or study area Y, superficially, as commonly happens in current society; rather we would have learners who possess sharp generic learning attributes $\mathrm{P}$ or $\mathrm{Q}$ for that matter, giving a more authentic and intrinsic identification of the learner.

\subsection{Authentic Education from the Viewpoints of Neuroscience}

\subsubsection{Emotions versus Intellect}

In more recent times, we have seen those who are interested and engaged in research in pedagogy are introducing an interesting new dimension, or viewpoint to the discipline. That is they try to understand and define learning from the point of view of neuroscience. In neuroscience, we study structure of human brain and nervous system and how they work. It would be very interesting and useful if we could understand learning from the perspective of neuroscience. In fact researchers have advanced significantly in the area though we have not yet seen any significant changes incorporated into pedagogical practices accordingly. Years ago, a long held belief was that intellect was of high significance and emotions are of much less significance from the point of view of learning; in fact emotions were associated with the heart, instead of the brain. From the research findings of neuroscience and other related areas, it has become clearer that the previously held belief was not quite accurate as it is understood that we cannot disentangle intellect from emotions, rather they are more inter-wound and inseparable from each other. As Sylwester (Sylwester, 1998) points out, there is no act of downshifting to emotions from intellect, as had previously conceived. All physical parts of the brain are important in its operation as a whole and emotions, in fact, guide this holistic 
operation. It is also evident from the study of gifted personal, both children and adults, that they show considerable emotional sensitivity. These studies align very well validating that emotions play a significant role in learning; deep emotions, if properly directed, can be used to motivate students for deep learning. In an authentic educational framework, emotional and other sensitivities of individuals are considered positively as enriching diversity within a society; possible important contributions from such individuals are widely accepted and made aware of.

\subsubsection{Growth of Dendrites throughout Lifespan}

Studies from neuroscience also reveal that when deep learning takes place through enrichment, brain cells, or neurons, or more specifically receptive parts called dendrites, grow physically to make more communication connections among them; dendrites receives inputs from other nerve cells and are very responsive to these inputs, increasing in number and length in use while decreasing in disuse. This growth of dendrites takes place within the cerebral cortex of the brain that deals with higher cognitive processing. Another important point is the growth of these dendrites could happen throughout the life span, not restricted to any age limit (Diamond, 1996; Diamond, 2001). Thus, as educators, it is very important for us to provide enriching, deep learning environments for our learners, irrespective of any age restrictions; they have capacities to be benefited from conducive environments. The significance of widely discussed concept of lifelong learning needs highlighting here; human beings have the capacities to be benefited from enriched continued learning that result in growth of dendrites of nerve cells. In other words, even if one engages in some routine work to earn a living, he or she may attend to some challenging learning activities continuously for personal growth. Advances in imaging techniques have helped visualising the physical structures and operations of the brain; functional magnetic resonance imaging (fMRI) is such a technique used. This leads to the significant finding that learning has physical meaning to it, not just a concept or matter of committing information logically to memory. When more and more deep and enriched learning takes place, a denser network of cells is created in the brain. This concept can also be viewed from pedagogical point as well. Kolb's experiential cycle is a widely used explanation on how effective learning takes place (Zull, 2002; Healey and Jenkins, 2000). Kolb's cycle has four stages, namely concrete experience stage, reflective observation stage, abstract conceptualisations stage and active experimentation stage. All four stages play important roles in accomplishing learning. Kolb's theory explains how different parts of the brain function together to affect effective learning. Authentic education experience as a deep learning and critical thinking approach allow individuals to utilise most parts of their brains with the possibility of creating a denser neural network. Personnel with integrator type characteristics of looking at things from multi-dimensional perspectives, or more creatively, are likely to have denser neural networks; they are also the ones with high emotional and other sensitivity levels.

2.4 Authentic Education from the Viewpoints of Machine Learning, Computer Science and Artificial Neural Networks

\subsubsection{Human Brain as a Parallel Processor as Opposed to Sequential Machine}

Computer scientists have found that typical computers are more capable of solving problems that require sequential operation and find that in some situations that alone is not adequate. Typical computers are capable of executing routine steps sequentially at a very high speed. Human brain functions in a quite different manner to that of the typical computer; that is as a parallel processor. Problems that require parallel processing requirements cannot be solved using typical computers; instead they need parallel processors, or some processors that operate similar to human brains. Computer scientists have succeeded in implementing artificial neural networks to some problems that require processing power that is similar but simpler to that of human brain. What is significant in these artificial neural networks is that they possess parallel processing features but are considerably slower than typical computers, which operate in a sequential manner. Artificial neural networks are also better suited for solving problems with a large number of inputs compared to typical computer operations (Beale and Jackson, 1990). We can make some very useful inferences here. The typical computers are better suited for finding solutions to problems that require routine operations and have relatively less number of inputs in a relatively quick time whereas human brains, or similar emulated systems, are better in finding solutions to more complex, or non-routine type, problems with large number of inputs and requiring parallel operations; the latter operations essentially take relatively more time, or slower. That is, typical computers perform large number of operations routinely to obtain results very fast, while the human brain naturally functions quite differently in a more complex manner, comparatively slowly. As an example, multiplication of two large numbers can very easily and quickly be done by using a computer whereas it will struggle with a task of pattern recognition where there is a function of generalisation involved. On the other hand a human brain would find a pattern recognition task involving generalisation easier and simpler compared to the multiplication task involving a large number of routine tasks. The typical tasks the computers perform are not usually categorised as learning; if 
computers or machines are to learn they need to emulate neural networks as that happens in artificial neural network systems. That is, though the computers or machines can perform routine tasks very fast, we do not consider them as intelligent or have the ability to learn; this feature of computers contrasts with human beings who have the ability to learn. Viewing from the point of Bloom's taxonomy, tasks of generalisation or synthesis are found at the higher end of the spectrum of learning inferring that human brains are naturally inclined for pursuing higher-order learning, as opposed to involving in mere application of knowledge in routine tasks targeting lower-order learning. Isn't this a good reason for us educators to design our curricular, including assessment, focusing higher order learning, or higher end of Bloom's taxonomy? Such designs are bound to yield more authentic experience of learning. We as educators want our learners to be thinking and reflecting human beings, but not machines that can operate routinely at very high speeds. We have seen more and more traditional routine tasks performed by humans are being automated to be done by machines or computers over the years. Let the machines do what they are better in doing and turn our attention to fostering creative and reflecting human beings through our pedagogical practices. Let us deviate from making our learners unthinking robots who can merely follow given instruction one after the other. This implies that in an authentic education framework, it is essential that human brain is considered as a parallel processor capable of generalising as opposed a machine of sequential operation, similar to a typical computer.

\section{Conclusion}

In this concluding section, the author presents vision of authentic education, having looked at it from a number of different perspectives. His attempt is to integrated different perspectives in to a more meaningful understanding.

Within an authentic education framework, learners' individual psychological and neurological characteristics are given consideration and accepted as they are, promoting inclusive practices. For example, emotional and other high sensitivities as commonly found in gifted and creative personnel are not considered as constraints, rather they enrich a neurodiverse society to operate in a more balanced manner. Learners with high developmental potential get conducive environments to reach higher levels of development, similar to self-actualised state. This aspect is more or less completely missing in current educational environments. That is, psychological and neurological aspects of learners are not given their due recognition. An authentic education system sends learners through a lasting deep learning and critical thinking experience, for which human brains are capable of under conducive teaching-learning environments; human brains are treated as parallel processors that are capable of dealing with multiple inputs and solving complex problems unlike machines, or computers that are good at executing routine steps in at very high speeds. Following the fundamentals of neuroscience, many physical parts of the brains are incorporated into learning with methodologies similar to Kolb's experiential learning cycle and constructivist theory of learning; learning has physical meaning in which neurons in the brain grow to develop dense communication network indicating deep learning, as opposed to surface, or superficial learning, has taken place. As a main conceptual difference from the current practices, we are not merely making our learners employable in a restricted area of application or knowledge; rather we make them broader in their knowledge and its applicable areas. They will be successful not only in their careers, but as whole individuals and how each one operates as a person within the society. In an authentic education framework, learning preferences of visual spatial learners and auditory sequential learners are given consideration equally and unbiasedly and these preferences are mapped into to related career paths such as integrator or implementer type work so that individuals of both categories enjoy their work more naturally, or intrinsically. Each individual will identify his or here authentic characteristics uniquely and is not ashamed of being one type or the other; the society as a whole pays respect for each category as it needs these diverse characteristics to cater its needs. In an authentic educational practice, learner evaluation is done using generic learning attributes that are associated with learners' intrinsic characteristics, instead of an indication of how well a learner has prepared prior to an assessment, or some extrinsic measures; these generic learning attributes carry qualitative values that are valid throughout one's life span as they relate to one's psychological and neurological characteristics very well. In support of these intrinsic psychological and neurological characteristics of individuals, there are work type classifications of implementer or integrator types so that an appropriate match can be made to make each individual more satisfying and at ease to his or her authentic nature.

In summary, the author's vision is a complete paradigm change in how our society operates; it is a complete social change. The essence of this change is the way we educate our learners that characterise how we assess them, socially accept their authentic beings and how we accommodate them to reach their full potential. 


\section{References}

Armstrong, T. (2011). The Power of Neurodiversity: Unleashing the Advantages of Your Differently Wired Brain. Da Capo Lifelong Books.

Beale, R., \& T. Jackson. (1990). Neural Computing - An Introduction. Institute of Physics Publishing. http://dx.doi.org/10.1887/0852742622

Biggs, J. (2003). Teaching for Quality Learning at University ( $2^{\text {nd }}$ ed.). Buckingham, Society for Research into Higher Education and Open University Press.

Dabrowski, K. (1972). Psychoneuroses Is Not An Illness. London: Gryf Publications

Dabrowski, K. (1977). Theory of Levels of Emotional Development (vol 1) - Multilevelness and Positive Disintegration. New York: Dabor Science Publications.

Dabrowski, K. (with Kawczak A. and Piechowski M. M.). (1970). Mental Growth through Positive Disintegration. London: Gryf Publications

DeLyser, R. R., Thompson, S. S, Edelstein, G., Lengsfeld, C., Rosa, A. J., Rullkoetter, P., Whitman, R., \& Whitt, M. (2003). Creating a Student Centered Learning Environment at the University of Denver. Journal of Engineering Education, 92(3), 269-273. http://dx.doi.org/10.1002/j.2168-9830.2003.tb00768.x

Diamond, M. C. (1996). The Brain... Use it or Lose It. New Horizons for Learning: School of Education, Johns Hopkins University. Retrieved from http://education.jhu.edu/newhorizons/Neurosciences/articles/

Diamond, M. C. (2001). Response of the Brain to Enrichment. New Horizons for Learning: School of Education, Johns Hopkins University. Retrieved from http:/education.jhu.edu/newhorizons/Neurosciences/articles/

Entwistle, N. J. (1998). Approaches to Learning and Forms of Understanding. In Teaching and Learning in Higher Education, ed. B. Dart and G. Boulton-Lewis, 72-101. Melbourne, Australia: Australian Council for Educational Research

Healey, M., \& Jenkins, A. (2000). Kolb's Experiential Learning Theory and Its Application in Geography in Higher Education. Journal of Geography, 99, 185-195.

Maslow, A. (1968). Toward a Psychology of Being. New York: Van Nostrand Reinhold.

Maslow, A. (1993). Farther Reaches of Human Nature. New York, N.Y., U.S.A.: Arkana.

Paul, R., \& L. Elder. (2000). Critical Thinking - Tools for Taking Charge of Your Learning and Your Life. Pearson Education.

Ramsden, P. (2003). Learning to Teach in Higher Education( $2^{\text {nd }}$ ed.). London: RoutledgeFalmer.

Silverman, L. K. (2002). Upside-Down Brilliance: The Visual-Spatial Learner. Denver: DeLeon Publishing.

Silverman, L. K. (2004). At-Risk Youth and the Creative Process. Paper presented at ARTernatives for At-Risk Youth Conference, May 14, Colorado Springs.

Silverman, L.K. (1998). Personality and Learning Styles of Gifted Children. In Excellence In Educating Gifted \& Talented Learners ( $3^{r d}$ ed), ed. Van Tassel - Baska, Denver, Colorado, USA: Love Publishing Company.

Sylwester, R. (1998). The Downshifting Dilemma: A Commentary and Proposal. New Horizons for Learning: School of Education, Johns Hopkins University. Retrieved http://education.jhu.edu/newhorizons/Neurosciences/articles/

Webb, J. T. (2008). Dabrowski's Theory and Existential Depression in Gifted Children and Adults. Paper presented at the Eighth International Congress of the Institute for Positive Disintegration in Human Development, August 7-9, Alberta, Canada.

Webb, J.T. (with Amend E. R., Webb N.E., Goerss J., Beljan P, and Olenchak F.R.) (2005). Misdiagnosis and Dual Diagnoses of Gifted Children and Adults: ADHD, Bipolar, Ocd, Asperger's, Depression, and Other Disorders. Great Potential Press.

Zull, J. E. (2002). The Art of Changing the Brain: Enriching the Practice of Teaching by Exploring the Biology of Learning. Stylus Publishing. 